\title{
EDIÇÃO TEMÁTICA - TELENUTRIÇÃO
}

\author{
Thematic Edition: Telenutrition
}

Inês Rugani Ribeiro de Castro'

A Educação a Distância (EAD) representa um importante desafio e uma grande oportunidade para a Universidade. $O$ desafio de se reinventar nos processos de ensino-aprendizagem e a oportunidade de ampliar suas práticas na perspectiva do cumprimento de sua missão de democratização do conhecimento e da formação e qualificação da força de trabalho em nosso país. A criação do Telessaúde em 2007 e sua consolidação ao longo desses anos expressam o esforço de diversas instituições no sentido de oferecer aos trabalhadores da saúde diferentes oportunidades de formação com vistas à qualificação do Sistema Único de Saúde.

ONúcleo Telessaúde Rio de Janeiro, localizado na UERJ, tem como uma de suasáreas de atuação a Nutrição, cujas atividades estão sob a responsabilidade do Instituto de Nutrição dessa universidade. Essa área de atuação está estruturada por meio do Telenutrição, projeto de extensão universitária que articula diversas iniciativas de EAD em Nutrição. Além de cursos a distância, seminários virtuais e teleconsultorias, esse projeto vem garantindo a transmissão virtual de eventos científicos dirigidos a profissionais e pesquisadores da área da saúde organizados pelo Programa de Pós-Graduação Alimentação Nutrição e Saúde, do Instituto de Nutrição. Essas atividades de EAD desenvolvidas pelo Telenutrição contribuem para a realização da missão da Universidade na perspectiva de consolidação das políticas públicas de saúde, de alimentação e nutrição e de segurança alimentar e nutricional, uma vez que todas essas políticas reconhecem, de diferentes formas, a formação da força de trabalho como elemento chave para sua plena realização.

O presente número do Jornal Brasileiro de Telessaúde traz o artigo "O uso de tecnologias de informação e comunicação na área da Nutrição", que apresenta uma reflexão baseada em uma sistematização das experiências acumuladas até o momento. Traz, também, três artigos que registram e analisam experiências do Telenutrição. Em “Estratégias de formação em alimentação escolar por meio do Telessaúde", são apresentadas as estratégias realizadas pelo Núcleo de Alimentação e Nutrição Escolar (NUCANE) em parceria com o Telessaúde. O desempenho de uma das iniciativas dessa parceria está apresentado no artigo "Avaliação do curso a distância'promoção da alimentação saudável no ambiente escolar' ministrado pelo Telenutrição-RJ'. Por fim, um balanço sobre as teleconsultorias é apresentado no artigo “Potencialidades das atividades de teleconsultorias em nutrição".

Esperamos que as reflexões aqui apresentadas contribuam para a ampliação, consolidação e melhoria das práticas de EAD desenvolvidas na área de alimentação e nutrição.

1. Professora associada e diretora do Instituto de Nutrição - UERJ 